\title{
Does Increased Adenoma Detection Reduce the Risk of Colorectal Cancer, and How Good
}

\section{Do We Need to Be?}

\author{
Christen K. Dilly, MD, MEHP ${ }^{1,2}$; Charles J. Kahi, MD, MS ${ }^{1,2}$ \\ ${ }^{1}$ Richard L. Roudebush VA Medical Center \\ ${ }^{2}$ Division of Gastroenterology, Hepatology and Nutrition, Indiana University School of Medicine
} Address correspondence to:

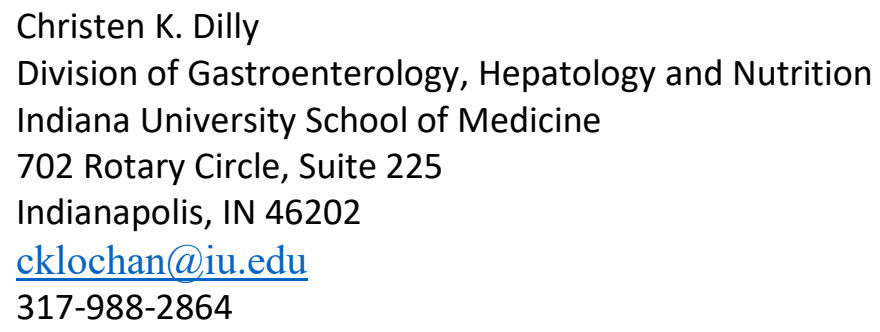

\begin{abstract}
Purpose of review: Colorectal cancer is largely preventable with colonoscopy and other screening modalities. However, the effectiveness of screening and surveillance depends on the quality of the colonoscopy exam. Adenoma detection rate is the best-validated metric by which we measure individual physicians' performance.
\end{abstract}

Recent findings: As we gather more data on the ADR, we are learning that older benchmarks may be inappropriately low. We have evidence that improving ADR leads to reductions in PCCRC. Two studies have demonstrated that when a colonoscopy is performed by physicians with higher ADRs, patients are less likely to have advanced adenomas on the first surveillance exam. Finally, there is at least some evidence that higher ADRs do not lead to more cumulative surveillance exams.

Summary: The ADR is a useful outcome measure that can provide individual endoscopists and their patients with information about the likelihood of their patients developing PCCRC. To

This is the author's manuscript of the article published in final edited form as:

Dilly, C. K., \& Kahi, C. J. (2019). Does Increased Adenoma Detection Reduce the Risk of Colorectal Cancer, and How Good Do We Need to Be? Current Gastroenterology Reports, 21(3), 9. https://doi.org/10.1007/s11894-019-0678-5 
achieve the lowest possible PCCRC rate, we should be striving for higher ADRs. While strategies and innovations may help a bit in improving ADRs, our efforts should focus on ensuring a complete mucosal exam for each patient. Behavioral psychology theories may provide useful frameworks for studying motivating factors that drive a careful exam.

Keywords: Screening, Colonoscopy, Quality

\section{Introduction}

Colonoscopy is performed not just to detect, but to prevent colorectal cancer (CRC). Adenomas are precursors to $\mathrm{CRC}$, and the goal of primary prevention, is to remove them before they progress to invasive cancer. Colonoscopy with polypectomy was initially thought to be associated with about $80 \%$ reduction in CRC incidence; however subsequent adenoma cohort studies have shown less impressive results. ${ }^{1}$ Early estimates of reduction of CRC incidence through removal of adenomas suggested a reduction of about $80 \%$ in cancer incidence, although later studies suggested. ${ }^{2,3}$ Our patients agree to undergo the invasive procedure because they trust that it will protect them from the disease. However, some physicians are more skilled than others at detecting and removing polyps, meaning patients are not equally protected against cancers. Measuring our outcomes can help us estimate the level of protection we provide and can motivate us to improve. The "ultimate" outcome is CRC mortality; fortunately, few endoscopists have enough patients in surveillance programs who die of CRC for mortality to be a useful measure of effectiveness, or a quality metric suitable for interventions. We therefore must use surrogate measures that provide us with more immediate data but that correlate with the ultimate outcome of CRC mortality. 


\section{The adenoma detection rate}

The best-established surrogate outcome measure is the adenoma detection rate (ADR). The ADR is "the proportion of screening colonoscopies performed by a physician that detect at least one histologically confirmed colorectal adenoma or adenocarcinoma."4 Initially only screening exams were used to calculate ADR, because we didn't want to contaminate our screening population with the effect of surveillance exams. Since then, we have learned that using a mix of screening and surveillance populations yields similar results as using exclusively screening populations when calculating ADR. There was concern that "indication gaming" might tempt some endoscopists to select the procedure indication as "screening" whenever he or she was confident that an adenoma had been removed, while using another indication if it was present and an adenoma had not been removed. However, when Rex and colleagues measured ADR using indication gaming and using true indications, they found that the ADR was similar in both measurement methods. ${ }^{5}$

The ADR is useful because it correlates with the post-colonoscopy colorectal cancer (PCCRC) rate. ${ }^{6}$ A PCCRC interval cancer is a cancer that is diagnosed after a screening or surveillance examination in which no cancer is detected, and before the date of the next recommended examination. ${ }^{7}$ In a landmark study, Corley and colleagues examined the correlation between ADR and risk of PCCRC death. They found that "physicians who increase their ADR from $<19 \%$ to $>34 \%$ might prevent 1 additional interval cancer over the next 10 years for every 213 colonoscopies performed," and that "each 1\% increase in ADR was associated with a 5\% decrease in the risk of a fatal interval CRC within the observed range of ADRs."4

Samadder and colleagues found that $6 \%$ of colon cancers detected were in patients who had had a colonoscopy at least six months but fewer than 5 years prior to the cancer diagnosis, 
which suggests that $6 \%$ of cancers detected were interval cancers. ${ }^{8}$ le Clerq and colleagues found that $86.4 \%$ of 147 PCCRCs were related to procedural factors (incomplete resection, missed lesions, inadequate exam/surveillance), while only $13 \%$ were truly aggressive cancers. ${ }^{9}$ Robertson and colleagues found that $71 \%$ of 58 PCCRCs were related to procedural factors, while $24 \%$ were aggressive cancers. ${ }^{10}$ Taken together, these data imply that improving procedural quality could bring the PCCRC rate closer to the theoretical minimum of $0.78-1.4 \%$ of cancers.

Kim and colleagues found that in patients with one or two adenomas, a low ADR for the endoscopist performing the baseline screening was as significant a risk factor for metachronous cancer as the number, size, and histology of adenomas at baseline. ${ }^{11}$ However, patients with no adenomas at screening had such a low risk of metachronous cancer that the endoscopist's ADR did not matter. This supports the findings by Robertson and colleagues that most of the risk of PCCRC comes from missed lesions, incomplete polypectomy, and improper surveillance intervals. $^{12}$

\section{What is an adequate ADR?}

Older American guidelines suggested that the ADR should be at least $15 \%$ in women and

$25 \%$ in men. ${ }^{13}$ As high-definition colonoscopes and multiple technological advances have come into use, much higher ADRs have been demonstrated in the recent literature. Kaminski and colleagues in 2017 divided their endoscopists into quartiles. The best group had a mean ADR of $31.3 \%$, and the worst had mean of $10.8 \% .{ }^{14}$ Their study population developed 168 interval cancers in 895,916 person-years of follow up, representing $10.1 \%$ of all cancers detected during a 5-year follow up. They found that those endoscopists who increased their ADR from the 
lowest to the highest quartile decreased their interval cancer rate from 25.3 cases $/ 100,000$ patient-years to 7.1 cases/100,000 patient-years. ${ }^{14}$ They showed that a benchmark of $24.6 \%$ was the threshold needed to reach a "profound and statistically significant reduction in the risk of interval colorectal cancer."

European performance measures indicate a minimum ADR of $>=25 \%$ when looking at all colonoscopies in patients 50 years and older, excluding emergencies and therapeutic indications; screening and surveillance exams are included together. ${ }^{15}$ Multiple studies have demonstrated that the ADR is higher in women physicians, gastroenterologists, and those with 9 or fewer years since residency training. ${ }^{16}$ The total ADR may not tell the whole story, as James and colleagues measured distal and proximal ADR for endoscopists and found that they are only modestly correlated..$^{17}$

So far, no study has found a "ceiling" for ADR, but there appears to be a steady decrease in interval cancer rate as ADR increases. Shaukat and colleagues developed a nonlinear Poisson regression model plotting the relationship between physicians' ADRs and the incidence of PCCRC..$^{18}$ It appears that the plateau for ADR is between 50-60\%; at this level, the incidence of PCCRC appears to be less than one cancer per 10,000 person-years. This appears to be significantly lower than what would be estimated based on CRC incidence data. The incidence of colorectal cancer was 40.7/100,000 person-years between 2009-2013. ${ }^{19}$ Using estimates that $13-24 \%$ of interval cancers are aggressive and not due to procedural factors, we would expect that an endoscopist who performs 500 colonoscopies per year for 10 years might see $0.3-0.56$ PCCRCs that he or she could not have prevented. Because an ADR of 50\% seems to correlate with a PCCRC rate lower than this estimated minimum, then $50 \%$ is probably a good estimate of the "ideal", "aspirational", or "ceiling" ADR. 


\section{How does ADR affect the surveillance interval?}

It is likely that endoscopists with very high ADRs are detecting more diminutive adenomas that are not necessarily clinically significant. This could lead to more frequent surveillance exams where little pathology is detected, increasing costs and risks without clear clinical benefit. Instead, we believe that finding diminutive polyps and taking the time to remove them is a marker of a more thorough exam.

The colonoscopist's ADR affects the yield of future colonoscopies. Mangas-Sanjuan and colleagues studied a higher-risk group, which was a cohort of patients who had an advanced adenoma detected on index exam. They found that the ADR of the colonoscopist who performed the baseline exam predicted finding advanced neoplasia at surveillance colonoscopy. ${ }^{20}$ Kim and colleagues studied a lower-risk group, which was patients who had no or only 1 or 2 non-

advanced adenomas at a baseline exam. ${ }^{11}$ They showed that when compared to physicians with a low ADR, if the physician performing an initial screening exam has a moderate or high ADR, and at least one adenoma was found at baseline, it was about 2/3 less likely that any neoplasia or an advanced adenoma would be found at the next surveillance exam. This effect did not reach statistical significance if no adenomas were found during the baseline exam. In this study, the "hidden risk" group, which had the highest risk of advanced neoplasia at follow up exam, had two adenomas on their initial exam and had their initial exam performed by a physician with a low ADR. Taken together, these studies suggest that unless the index exam is negative, the ADR of the endoscopist should impact our surveillance recommendations. Conversely, if an exam is performed by a physician who has a high ADR, we may be able to lengthen the screening interval. $^{21}$ 
When a colonoscopy is performed by a physician with a high ADR, there are two implications. First, it is more likely that one or more polyps will be found, which will shorten the surveillance interval from 10 to 5 or even 3 years. Second, it is less likely that a polyp will be left behind, which implies that the yield of the next exam will be lower. These patients are doubly protected; physicians with a high ADR protect their patients both by removing all pathology and by recommending shorter surveillance intervals. Physicians with a low ADR do their patients a double disservice, by missing pathology and by recommending inappropriately longer surveillance intervals. Conversely, some physicians seem to be aware that they are at risk of missing pathology and recommend shorter surveillance intervals than guidelines would recommend after a negative exam. It is not clear what effect these practice patterns have on PCCRC risk.

\section{Other measures of colonoscopy quality}

In addition to the ADR and the PCCRC rate, other measures have been proposed or used as markers of colonoscopy quality. "Adenomas per colonoscopy" (APC) has been suggested by an ACG/ASGE joint task force. ${ }^{22}$ When ADR is measured, some physicians will search less aggressively for polyps after the first adenoma is found, ${ }^{23}$ as removing additional polyps will lengthen the procedure without improving the ADR. The APC would reduce this tendency. However, to measure APC accurately, each polyp would need to be examined separately to confirm that it is an adenoma. This could generate increased costs for photography software or pathology. Hilsden and colleagues found that the ADR and APC were complementary; APC did a better job of discriminating between the lowest- and highest-performing endoscopists, but

some endoscopists achieved minimum benchmarks on one measure but not the other. ${ }^{24}$ 
Routinely reporting both measures may act as a motivating factor for physicians who are above the ADR benchmark but have room for improvement.

In the United States, withdrawal time (WT) is frequently tracked, which is the amount of time a physician spends examining the colonic mucosa after intubation and identification and photo documentation of the cecum landmarks of appendicular orifice and ileocecal valve, until the endoscope is withdrawn from the anus. ${ }^{2}$ Currently, WT is best used as a target for intervention for endoscopists who have low ADRs and short WTs. European performance measures include numerous pre- and post-procedure factors, such as bowel preparation, time slot for colonoscopy, polyp detection rate, appropriate polypectomy technique, polyp retrieval rate, tattooing resection sites, complication rate, patient experience, and appropriate post-polypectomy surveillance. ${ }^{15}$ The advanced adenoma detection rate has been suggested, with the rationale that these are more clinically meaningful lesions. However, size measurements are somewhat subjective. "Polyp detection rate" can be used, but this measurement can be gamed by removing clinically insignificant polyps. ${ }^{5}$ The serrated polyp detection rate has also been considered, as serrated lesions are more difficult to detect and contribute significantly to PCCRC. This measurement is problematic, however, because serrated neoplasia detection tends to correlate with that of adenomas especially for high-level detectors, and because of the significant inter-observer variability among pathologists in the interpretation of subtypes of serrated polyps.

\section{How can a physician improve his or her ADR?}

Some factors associated with a higher ADR are immutable, such as being female, being a gastroenterologist, and being in practice for less than nine years. ${ }^{16}$ However, other factors can be 
changed. A combination of feedback, benchmarking and training has been most effective in improving ADRs. Many physicians improve gradually over time when they know they are being monitored. For example, multiple studies using performance feedback have shown that ADR improves steadily throughout the duration of the tracking period. ${ }^{21,25}$ A meticulous and compulsive mucosal inspection technique is critical. Interestingly, attempts at re-training after entering practice have been met with mixed results. Interventions that have been studied to determine the effect on improving ADR are summarized in Table 1. There is insufficient evidence to recommend for or against the use of specific bowel preparations, $\mathrm{CO} 2$ insufflation, Propofol sedation, antispasmodics, or position changes for the purpose of improving ADR.

\section{Negative effects of increasing ADR}

While the GI field is focused on improving the ADR, there are some potential downsides to this goal. Modeling has projected an increased burden of surveillance endoscopies that are recommended after adenoma removal. ${ }^{14}$ However, in the study by Mangas-Sanjuan and colleagues, a high ADR was not associated with more frequent surveillance. ${ }^{20}$ Procedure times may be longer due to time spent on careful mucosal inspection and on removing pathology. The clinical benefit of removing diminutive polyps is not clear, since the vast majority of these will not progress to invasive cancer. Patients may experience anxiety after being labelled "high-risk" when more than two adenomas are found, as current guidelines recommend the same surveillance interval for patients with a few diminutive adenomas as for those with a histologically advanced adenoma. Finally, there is the concern about increased complication 
rates due to more frequent surveillance exams; however, in multiple studies, the perforation rate was the same for those who improved ADR and those who did not $(0.02 \%$ for both groups $) .{ }^{14}$ Furthermore, Brenner and colleagues found that as ADR improved, bleeding and perforation rates were stable over 10 years. $^{21}$

\section{Why do some physicians lack motivation to improve?}

If there are so many methods available that help improve the ADR, why do some individual physicians not adopt them? A number of factors might be at play. Michie and colleagues studied psychological theories that influence behavior change when implementing evidence-based medicine guidelines. They developed a list of 12 domains that could be studied to learn more about behavior change. ${ }^{26}$ This study illustrates that informing physicians about the importance of a practice and ensuring that they have the skills to change their behavior are only part of the process; many additional factors determine whether they will implement the change. For example, if physicians lack the self-efficacy to believe that they are capable of achieving an ADR of $50 \%$, it is unlikely that they will make significant efforts toward achieving that goal. If the endoscopy unit environment is not designed to allow for ample withdrawal times, then competing pressures will outweigh physicians' motivation to spend more time examining. If group norms in the environment stress productivity over ADR and other metrics, physicians will strive for higher productivity. It has also been proposed that obsessive-compulsive or other personality traits may be more prominent in endoscopists with a high ADR, and these traits are more difficult to impact.

For those who are not receiving feedback in the form of ADR, withdrawal times, or interval cancer rates, the Dunning-Kruger effect might be playing a role. ${ }^{27}$ In the studies 
conducted by Dunning \& Kruger, subjects assessed their own skills as being about average when they were significantly below average. This finding suggests that endoscopists who have a below-average ADR may not believe their skills are inferior to their colleagues' skills.

For those who are aware that their ADR is below average but choose not to adopt new methods or technology to improve their skills, it may be difficult to see the benefit of improving the ADR. For example, Kaminski and colleagues found that endoscopists who increased their ADR from the lowest (10.8\%) to the highest quartile (31.1\%) decreased their interval cancer rate from 25.3 cases/100,000 patient-years to 7.1 cases/100,000 patient-years. ${ }^{14}$ The event of an interval cancer is so rare that an individual endoscopist is very unlikely to notice a difference after improving his/her ADR. The benefit is seen at the population level, when the pool of physicians improves its collective ADR. When weighing the cost of additional training, additional equipment, and the additional time they would spend on each exam doing a more thorough mucosal examination, many physicians cannot perceive the benefit of a possibly seeing a few fewer interval cancers as justifying those costs. Furthermore, the cost of treating invasive cancer would be borne by the patient/insurance company, not by the endoscopist. In his landmark work on game theory, Thomas Schelling wrote of the difficulty convincing people to act to benefit the greater good when they are motivated by personal reward. ${ }^{28}$ Daniel Kanneman's theory of loss aversion also partially explains this. He argues that it is difficult for people to choose to act when the outcome being prevented is in the future, the effects are uncertain, and the action involves personal cost. ${ }^{29}$ Certainly the outcome of a PCCRC would fit these criteria.

Because the outcome of interval cancer is so rare, and because physicians may not even learn of an interval cancer found in their patients, surrogate outcomes such as ADR and 
withdrawal time are used for more immediate feedback. However, if physicians do not appreciate the correlation between these surrogate markers and PCCRCs, they may place less importance on improving these measures. Indeed, there are "ADR deniers" who may be skeptical that it is a useful metric and disregard their audit data. This can likely be explained using some of the behavioral psychology theories described above, but further study of this might help inform future interventions.

\section{Conclusion - The future of screening}

In the ideal situation, the ADR would inform screening and surveillance recommendations, in addition to patient risk factors and colonoscopy findings. A screening colonoscopy done by a physician who has an aspirational ADR imparts a high degree of protection against CRC. If no adenomas are found, the patient can avoid another exam for at least 10 years, and if adenomas are found, then surveillance intervals longer than the conventional 3 or 5 years can be considered, based on details of adenoma findings. If the initial exam is performed by a physician with an ADR just above established benchmarks, then established screening and surveillance intervals would need to be followed. More research is needed before recommendations could be provided if the initial exam is performed by a physician who does not meet minimum benchmarks.

Future studies might explore the best surveillance interval after a colonoscopy is performed by a physician with an aspirational ADR. It would also be valuable to apply behavioral psychology theories to the practice of colonoscopy; learning how to motivate physicians to perform a complete mucosal exam could have a major impact on the PCCRC rate.

\section{Key points}


- The adenoma detection rate (ADR) is now well-established as a marker of risk for postcolonoscopy colorectal cancer (PCCRC).

- Improving one's ADR is correlated with a reduction in the PCCRC rate.

- Existing benchmarks for adequate ADRs may be too low to provide adequate protection from PCCRC.

- While techniques and technology are available that make minor contributions to improving ADR, the most important factor is a complete mucosal exam.

- Behavioral psychology theories may provide useful frameworks for studying factors that motivate endoscopists to perform a careful exam.

\section{Acknowledgements}

The authors wish to thank Laura Menard, MLS, for her assistance with the literature search for this project.

\section{References}

1. Hewett DG, Kahi CJ, Rex DK. Does colonoscopy work? J Natl Compr Canc Netw 2010;8:67-76; quiz 77.

2. *Sullivan JF, Dumot JA. Maximizing the Effectiveness of Colonoscopy in the Prevention of Colorectal Cancer. Surg Oncol Clin N Am 2018;27:367-376.

- Good review of the evidence for use of ADR and techniques to maximize ADR.

3. Zauber AG, Winawer SJ, O'Brien MJ, et al. Colonoscopic polypectomy and long-term prevention of colorectal-cancer deaths. N Engl J Med 2012;366:687-96.

4. Corley DA, Levin TR, Doubeni CA. Adenoma detection rate and risk of colorectal cancer and death. The New England journal of medicine 2014;370:2541.

5. Rex DK, Ponugoti PL. Calculating the adenoma detection rate in screening colonoscopies only: Is it necessary? Can it be gamed? Endoscopy 2017;49:1069-1074.

6. Kaminski MF, Regula J, Kraszewska E, et al. Quality indicators for colonoscopy and the risk of interval cancer. N Engl J Med 2010;362:1795-803.

7. Sanduleanu S, le Clercq CM, Dekker E, et al. Definition and taxonomy of interval colorectal cancers: a proposal for standardising nomenclature. Gut 2015;64:1257-67.

8. Samadder NJ, Curtin K, Tuohy TMF, et al. Characteristics of missed or interval colorectal cancer and patient survival: A population-based study. Gastroenterology 2014;146:950-960.

9. le Clercq CMC, Bouwens MWE, Rondagh EJA, et al. Postcolonoscopy colorectal cancers are preventable: a population-based study. Gut 2014;63:957-963. 
10. $\quad * *$ Rex DK, Boland CR, Dominitz JA, et al. Colorectal Cancer Screening: Recommendations for Physicians and Patients From the U.S. Multi-Society Task Force on Colorectal Cancer. Gastroenterology 2017;153:307-323.

- $\quad$ Provides the multi-society task force recommendations on colorectal cancer screening.

11. *Kim TJ, Kim ER, Hong SN, et al. Adenoma detection rate influences the risk of metachronous advanced colorectal neoplasia in low-risk patients. Gastrointestinal Endoscopy 2018;87:809817.e1.

- Found that in patients with low-risk adenomas on baseline colonoscopy, the ADR of the initial endoscopist correlated with finding advanced adenomas on surveillance.

12. Robertson DJ, Lieberman DA, Winawer SJ, et al. Colorectal cancers soon after colonoscopy: a pooled multicohort analysis. Gut 2014;63:949-56.

13. Rex DK, Petrini JL, Baron TH, et al. Quality indicators for colonoscopy. Am J Gastroenterol 2006;101:873-85.

14. **Kaminski MF, Wieszczy P, Rupinski M, et al. Increased Rate of Adenoma Detection Associates With Reduced Risk of Colorectal Cancer and Death. Gastroenterology 2017;153:98-105.

- Very important study confirming the assumption that an increase in ADR correlates with a decreased risk for PCCRC.

- $\quad$ ADRs were quite low in this study.

15. Kaminski MF, Thomas-Gibson S, Bugajski M, et al. Performance measures for lower gastrointestinal endoscopy: a European Society of Gastrointestinal Endoscopy (ESGE) Quality Improvement Initiative. Endoscopy 2017;49:378-397.

16. *Mehrotra A, Morris M, Gourevitch RA, et al. Physician characteristics associated with higher adenoma detection rate. Gastrointestinal Endoscopy 2018;87:688-694.e2.

- Demonstrated that female gender, specializing in gastroenterology, and practicing for less than or equal to 9 years are characteristics associated with a higher ADR.

17. *James $\mathrm{P}$, Hegagi $\mathrm{M}$, Hegagi $\mathrm{M}$, et al. Variable Endoscopist performance in proximal and distal adenoma detection during colonoscopy: A retrospective cohort study. BMC Gastroenterology 2018;18.

- Showed that ADR in the proximal and distal colon is only modestly correlated, and that physicians with the highest overall ADRs were above the median in both segments.

18. Shaukat A, Rector TS, Church TR, et al. Longer Withdrawal Time Is Associated With a Reduced Incidence of Interval Cancer After Screening Colonoscopy. Gastroenterology 2015;149:952-7.

19. Siegel RL, Miller KD, Fedewa SA, et al. Colorectal cancer statistics, 2017. CA Cancer J Clin 2017;67:177-193.

20. $* *$ Mangas-Sanjuan C, Zapater P, Cubiella J, et al. Importance of endoscopist quality metrics for findings at surveillance colonoscopy: The detection-surveillance paradox. United European Gastroenterology Journal 2018;6:622-629.

- Looked at patients from the COLONPREV study who had advanced adenomas on surveillance and determined the ADR and number of adenomas per colonoscopy of the physician who had performed the initial exam. On both univariate and multivariate analysis, they showed that the ADR of the initial physician correlated with finding an advanced adenoma at followup.

- They showed that high ADR did not lead to more frequent surveillance colonoscopies.

21. Brenner $\mathrm{H}$, Altenhofen $\mathrm{L}$, Kretschmann J, et al. Trends in adenoma detection rates during the first 10 years of the German screening colonoscopy program. Gastroenterology 2015;149:356366.e1.

22. Rex DK, Schoenfeld PS, Cohen J, et al. Quality indicators for colonoscopy. Gastrointest Endosc 2015;81:31-53. 
23. Wang HS, Pisegna J, Modi R, et al. Adenoma detection rate is necessary but insufficient for distinguishing high versus low endoscopist performance. Gastrointest Endosc 2013;77:71-8.

24. Hilsden RJ, Bridges R, Dube C, et al. Defining Benchmarks for Adenoma Detection Rate and Adenomas per Colonoscopy in Patients Undergoing Colonoscopy Due to a Positive Fecal Immunochemical Test. American Journal of Gastroenterology 2016;111:1743-1749.

25. Kahi CJ, Ballard D, Shah AS, et al. Impact of a quarterly report card on colonoscopy quality measures. Gastrointest Endosc 2013;77:925-31.

26. Michie $\mathrm{S}$, Johnston $\mathrm{M}, \mathrm{Abraham} \mathrm{C}$, et al. Making psychological theory useful for implementing evidence based practice: a consensus approach. Qual Saf Health Care 2005;14:26-33.

27. Kruger J, Dunning D. Unskilled and unaware of it: how difficulties in recognizing one's own incompetence lead to inflated self-assessments. J Pers Soc Psychol 1999;77:1121-34.

28. Schelling TC. The strategy of conflict. Cambridge,: Harvard University Press, 1960.

29. Kahneman D. Thinking, fast and slow. New York: Farrar, Straus and Giroux, 2011.

30. Coe SG, Crook JE, DiehI NN, et al. An endoscopic quality improvement program improves detection of colorectal adenomas. Am J Gastroenterol 2013;108:219-26; quiz 227.

31. Coe SG, Panjala C, Heckman MG, et al. Quality in colonoscopy reporting: an assessment of compliance and performance improvement. Dig Liver Dis 2012;44:660-4.

32. *Wallace MB, Crook JE, Thomas CS, et al. Effect of an endoscopic quality improvement program on adenoma detection rates: a multicenter cluster-randomized controlled trial in a clinical practice setting (EQUIP-3). Gastrointestinal Endoscopy 2017;85:538-545.e4.

- Randomized trial of the training program that had previously been shown to be effective in a limited setting, but the trial was negative, possibly due to an unexpected improvement in the control group related to audit \& feedback.

33. Barclay RL, Vicari JJ, Greenlaw RL. Effect of a time-dependent colonoscopic withdrawal protocol on adenoma detection during screening colonoscopy. Clin Gastroenterol Hepatol 2008;6:1091-8.

34. *Rex DK. Polyp detection at colonoscopy: Endoscopist and technical factors. Best Practice and Research: Clinical Gastroenterology 2017;31:425-433.

- Good review of factors that contribute to ADR

35. Leung WK, Lo OS, Liu KS, et al. Detection of colorectal adenoma by narrow band imaging (HQ190) vs. high-definition white light colonoscopy: a randomized controlled trial. Am J Gastroenterol 2014;109:855-63.

36. Brown SR, Baraza W, Din S, et al. Chromoscopy versus conventional endoscopy for the detection of polyps in the colon and rectum. Cochrane Database of Systematic Reviews 2016.

37. Hafner S, Zolk K, Radaelli F, et al. Water infusion versus air insufflation for colonoscopy. Cochrane Database Syst Rev 2015:CD009863.

38. Kushnir VM, Oh YS, Hollander T, et al. Impact of retroflexion vs. second forward view examination of the right colon on adenoma detection: a comparison study. Am J Gastroenterol 2015;110:415-22.

39. Kaminski MF, Anderson J, Valori R, et al. Leadership training to improve adenoma detection rate in screening colonoscopy: a randomised trial. Gut 2016;65:616-24.

40. Pohl H, Bensen SP, Toor A, et al. Cap-assisted colonoscopy and detection of Adenomatous Polyps (CAP) study: a randomized trial. Endoscopy 2015;47:891-7.

41. Chin M, Karnes W, Jamal MM, et al. Use of the Endocuff during routine colonoscopy examination improves adenoma detection: A meta-analysis. World J Gastroenterol 2016;22:9642-9649.

42. Bhattacharyya R, Chedgy F, Kandiah K, et al. Endocuff-assisted vs. standard colonoscopy in the fecal occult blood test-based UK Bowel Cancer Screening Programme (E-cap study): a randomized trial. Endoscopy 2017;49:1043-1050. 
43. Hassan C, Senore C, Radaelli F, et al. Full-spectrum (FUSE) versus standard forward-viewing colonoscopy in an organised colorectal cancer screening programme. Gut 2017;66:1949-1955.

Table - Interventions aimed at improving ADR (original)

\begin{tabular}{|c|c|c|c|}
\hline Method & Population studied & Effect on ADR & Limitations \\
\hline \multirow{2}{*}{$\begin{array}{l}\text { Training in } \\
\text { withdrawal technique } \\
\text { and lesion } \\
\text { identification }\end{array}$} & $\begin{array}{l}\text { EQUIP } 1 \& 2 \text { - Average } \\
\text { ADR } 36 \%\end{array}$ & $\begin{array}{l}\text { ADR improved to } 47 \%{ }^{30} \text { and } \\
\text { remained improved after } 5 \\
\text { months. }{ }^{31}\end{array}$ & \\
\hline & $\begin{array}{l}\text { EQUIP-3 - Average } \\
\text { ADR } 31 \% \text { in the } \\
\text { intervention group, } 36 \% \\
\text { in the control group }\end{array}$ & $\begin{array}{l}\text { ADR improved by } 12 \% \text { in the } \\
\text { intervention group, but } \\
\text { endoscopists receiving passive } \\
\text { monitoring improved by } 4 \% .{ }^{32}\end{array}$ & \\
\hline $\begin{array}{l}\text { Mandating a } \\
\text { minimum withdrawal } \\
\text { time for each of four } \\
\text { segments }\end{array}$ & $\begin{array}{l}\text { Single-center study, } \\
\text { physicians were asked to } \\
\text { spend at least } 2 \text { minutes } \\
\text { per colon segment }\end{array}$ & $\begin{array}{l}\text { Mean ADR improved from } \\
23.5 \% \text { before to } 34.7 \% \text { after the } \\
\text { intervention. }{ }^{33}\end{array}$ & $\begin{array}{l}\text { Mandating a } \\
\text { withdrawal time } \\
\text { for the whole } \\
\text { exam has not } \\
\text { led to } \\
\text { improvements } \\
\text { in ADR. } \\
\text { Instead, } \\
\text { endoscopists } \\
\text { should focus on } \\
\text { mastering the } \\
\text { technique of } \\
\text { effective } \\
\text { mucosal } \\
\text { exposure, as this } \\
\text { will naturally } \\
\text { lead to longer } \\
\text { withdrawal } \\
\text { times. }{ }^{34}\end{array}$ \\
\hline $\begin{array}{l}\text { Switching to high- } \\
\text { definition } \\
\text { endoscopes }\end{array}$ & $\begin{array}{l}\text { Meta-analysis; mixed } \\
\text { population }\end{array}$ & $\begin{array}{l}\text { incremental yield of } 3.5 \% \text { for } \\
\text { small adenomas but not for } \\
\text { larger or more advanced } \\
\text { neoplasia. }^{2}\end{array}$ & \\
\hline $\begin{array}{l}\text { Use of narrow band } \\
\text { imaging }\end{array}$ & Control ADR of $34.4 \%$ & $\begin{array}{l}\text { ADR improved to } 48.3 \% \text { in } 190- \\
\text { NBI group. Polyp detection also } \\
\text { increased, without a difference } \\
\text { in adenoma miss rate. }{ }^{35}\end{array}$ & $\begin{array}{l}\text { NBI on older } \\
\text { scopes was } \\
\text { darker and not } \\
\text { as effective }\end{array}$ \\
\hline $\begin{array}{l}\text { Dye-based } \\
\text { Chromoendoscopy }\end{array}$ & $\begin{array}{l}\text { Meta-analysis (mixed } \\
\text { population) }\end{array}$ & $\begin{array}{l}\text { increase of } 30 \%(0.33 \text { lesions }) \text { in } \\
\text { adenoma detection, but with } \\
\text { increased cost and procedure } \\
\text { duration }^{36}\end{array}$ & $\begin{array}{l}\text { Only one study } \\
\text { used high- } \\
\text { definition } \\
\text { colonoscopes as } \\
\text { controls }\end{array}$ \\
\hline $\begin{array}{l}\text { Water exchange } \\
\text { colonoscopy }\end{array}$ & $\begin{array}{l}\text { Baseline ADR not } \\
\text { reported }\end{array}$ & $\begin{array}{l}\text { Higher ADR with water } \\
\text { immersion/exchange vs. air } \\
(36.3 \% \text { vs. } 31.4 \%)^{37}\end{array}$ & \\
\hline
\end{tabular}




\begin{tabular}{|c|c|c|c|}
\hline $\begin{array}{l}\text { Second examination } \\
\text { of the right colon } \\
\text { (either retroflexed or } \\
\text { in forward view) }\end{array}$ & $30.2-34 \%$ on first pass & $\begin{array}{l}7.5 \% \text { had an additional adenoma } \\
\text { in retroflexion, } 10.5 \% \text { had an } \\
\text { additional adenoma on } 2^{\text {nd }} \\
\text { forward view exam; there was } \\
\text { no difference between } \\
\text { techniques }^{38}\end{array}$ & $\begin{array}{l}\text { mean } \\
\text { withdrawal time } \\
\text { in these studies } \\
\text { was } 12.5 \\
\text { minutes, so it is } \\
\text { possible that the } \\
\text { increased ADR } \\
\text { is related to a } \\
\text { longer } \\
\text { withdrawal time } \\
\text { and not } \\
\text { necessarily to } \\
\text { the method of } \\
\text { examination }\end{array}$ \\
\hline $\begin{array}{l}\text { Reporting ADR to } \\
\text { physicians }\end{array}$ & $\begin{array}{l}\text { Tertiary-care VA with } \\
\text { six physicians }\end{array}$ & $\begin{array}{l}\text { Mean ADR increased from } \\
44.7 \% \text { before to } 53.9 \% \text { after } \\
\text { implementing quarterly report } \\
\text { cards. } .^{25}\end{array}$ & \\
\hline Leadership training & $\begin{array}{l}\text { Polish study where } \\
\text { center leaders underwent } \\
\text { intensive training }\end{array}$ & $\begin{array}{l}\text { ADR for not just the participant } \\
\text { leaders, but for the facilities led } \\
\text { by participants improved from a } \\
\text { mean of } 18.4 \% \text { to } 24.1 \% .{ }^{39}\end{array}$ & \\
\hline $\begin{array}{l}\text { Cap-assisted } \\
\text { colonoscopy }\end{array}$ & $\begin{array}{l}\text { Board-certified } \\
\text { gastroenterologists at } \\
\text { two centers (one VA), } \\
\text { using } 180 \text { scopes }\end{array}$ & $\begin{array}{l}\text { No difference in ADR between } \\
\text { cap-assisted or standard exam } \\
(60 \% \text { vs. } 57 \%)^{40}\end{array}$ & \\
\hline \multirow[t]{2}{*}{ Endocuff } & $\begin{array}{l}\text { Meta-analysis of studies } \\
\text { from multiple } \\
\text { international sites, but } \\
\text { mostly academic } \\
\text { hospitals }\end{array}$ & $\begin{array}{l}\text { ADR in Endocuff group was } \\
50.4 \% \text {, compared to } 43.3 \% \text { in } \\
\text { standard colonoscopy group. }{ }^{41}\end{array}$ & \multirow{2}{*}{$\begin{array}{l}\text { It appears that } \\
\text { the Endocuff } \\
\text { was more useful } \\
\text { in groups where } \\
\text { the control ADR } \\
\text { was lower. The } \\
\text { device has } \\
\text { subsequently } \\
\text { been replaced } \\
\text { by the Endocuff } \\
\text { Vision, which } \\
\text { has not been } \\
\text { extensively } \\
\text { studied. }\end{array}$} \\
\hline & $\begin{array}{l}\text { Single-center RCT in } \\
\text { the UK }\end{array}$ & $\begin{array}{l}\text { No significant difference } \\
\text { between ADR in Endocuff } \\
\text { group }(60.9 \%) \text { and standard } \\
\text { group }(63.0 \%) .{ }^{42}\end{array}$ & \\
\hline FUSE & $\begin{array}{l}\text { Regional screening } \\
\text { program of FIT-positive } \\
\text { patients }\end{array}$ & $\begin{array}{l}\text { No significant difference in } \\
\text { ADR between FUSE }(43.6 \%) \\
\text { and standard forward view } \\
(45.5 \%){ }^{43}\end{array}$ & $\begin{array}{l}\text { Several other } \\
\text { devices are } \\
\text { available } \\
\text { (mostly outside } \\
\text { the US) to } \\
\text { improve the } \\
\text { field of view, } \\
\text { and these } \\
\text { generally result } \\
\text { in an }\end{array}$ \\
\hline
\end{tabular}




\begin{tabular}{|l|l|l|}
\hline & & $\begin{array}{l}\text { improvement in } \\
\text { ADR by about } \\
7 \%, \text { but the cost } \\
\text { of these devices } \\
\text { precludes } \\
\text { routine use. }{ }^{34}\end{array}$ \\
\hline
\end{tabular}

